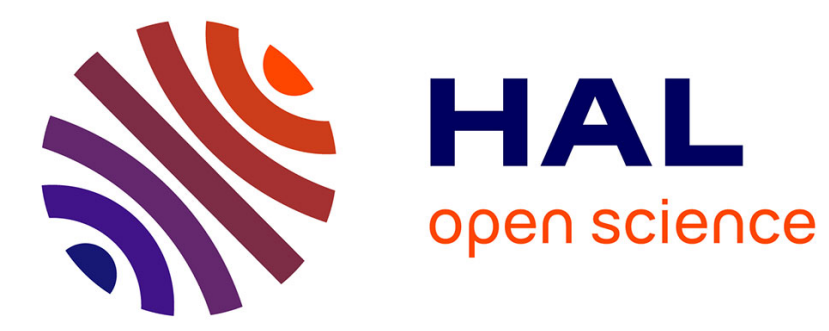

\title{
Structural and magnetic properties of the interstitial carbide-hydride NdScSiC0.5H0.2
}

\author{
Tadhg Mahon, Etienne Gaudin, V. Nassif, Sophie Tencé
}

\section{To cite this version:}

Tadhg Mahon, Etienne Gaudin, V. Nassif, Sophie Tencé. Structural and magnetic properties of the interstitial carbide-hydride NdScSiC0.5H0.2. Journal of Alloys and Compounds, 2020, 844, pp.156105. 10.1016/j.jallcom.2020.156105 . hal-02937763

\section{HAL Id: hal-02937763 \\ https://hal.science/hal-02937763}

Submitted on 14 Sep 2020

HAL is a multi-disciplinary open access archive for the deposit and dissemination of scientific research documents, whether they are published or not. The documents may come from teaching and research institutions in France or abroad, or from public or private research centers.
L'archive ouverte pluridisciplinaire HAL, est destinée au dépôt et à la diffusion de documents scientifiques de niveau recherche, publiés ou non, émanant des établissements d'enseignement et de recherche français ou étrangers, des laboratoires publics ou privés. 


\title{
Structural and magnetic properties of the interstitial carbide-hydride $\mathrm{NdScSiC}_{0.5} \mathrm{H}_{0.2}$
}

\author{
Authors \\ Tadhg MAHON ${ }^{1}$, Etienne GAUDIN ${ }^{1}$, Vivian NASSIF ${ }^{2}$, and Sophie TENCÉ ${ }^{1}$ \\ ${ }^{1}$ CNRS, Univ. Bordeaux, Bordeaux INP, ICMCB, UMR 5026, F-33600 Pessac, France \\ ${ }^{2}$ Institut Laue-Langevin, 71 avenue des Martyrs, CS 20156, 38042 Grenoble cedex 9, France \\ Corresponding author : sophie.tence@icmcb.cnrs.fr
}

\begin{abstract}
We report the synthesis of the first carbide-hydride phase obtained in the family of equiatomic intermetallics $R T X(R=$ rare earth, $T=$ transition metal, $X=p$-block element $)$ by insertion of light elements. We prepared the $\mathrm{NdScSiC}{ }_{0.5} \mathrm{H}_{0.2}$ compound by solid-gas reaction, by exposing the carbide $\mathrm{NdScSiC}_{0.5}$ to 40 bars of $\mathrm{H}_{2}$ gas at $450^{\circ} \mathrm{C}$. It crystallizes in the $\mathrm{La}_{2} \mathrm{Fe}_{2} \mathrm{Se}_{2} \mathrm{O}_{3}$-type structure with $\mathrm{H}$ and $\mathrm{C}$ atoms occupying $\mathrm{Nd}_{4}$ tetrahedral and $\mathrm{Nd}_{2} \mathrm{Sc}_{4}$ octahedral interstices, respectively. The $\mathrm{H}$ site is only partly filled owing to the presence of $\mathrm{Nd}-\mathrm{C}$ covalent bonding that prevents the formation of $\mathrm{Nd}-\mathrm{H}$ bonding through antagonist effect. The carbide-hydride was characterized through magnetic measurements, specific heat and powder neutron diffraction. Remarkably, hydrogenation of the carbide provokes a quite drastic effect on the magnetic properties by changing the ground state from a ferromagnetic $\left(\mathrm{T}_{\mathrm{C}} \sim 70 \mathrm{~K}\right)$ to an antiferromagnetic one $\left(\mathrm{T}_{\mathrm{N}}=10 \mathrm{~K}\right)$. The magnetic structure of $\mathrm{NdScSiC}_{0.5} \mathrm{H}_{0.2}$ consists of double layers of ferromagnetic $\mathrm{Nd}$ moments aligned along the $c$-axis and coupled antiferromagnetically along this axis. This magnetic structure results in a field-induced metamagnetic behaviour as pointed out by magnetization isotherms.
\end{abstract}

\section{Keywords}

Carbide-hydride, intermetallic, neutron diffraction, magnetic structure

\section{Introduction}

The insertion of light elements in intermetallic compounds is a powerful method of varying the physical properties of these systems. In particular, the insertion of elements like hydrogen, carbon and nitrogen has been largely investigated to improve and tune the magnetic properties of intermetallics such as Curie temperatures, saturated magnetization values or magnetic anisotropy. The possibility of combining several elements simultaneously has been studied to a much lower extent, essentially for tuning the properties of permanent magnets or magnetocaloric materials. Insertion of hydrogen is usually achieved by solid-gas reaction with $\mathrm{H}_{2}$ while carbon insertion can be realized by different ways: solid-gas reaction 
with acetylene or methane, solid-state reaction, decomposition of anthracene or direct melting of the elements or pristine intermetallic with graphite. The insertion of carbon and hydrogen atoms in the $\mathrm{R}_{2} \mathrm{Fe}_{17}$-type permanent magnets ( $\mathrm{R}=$ rare earth, especially $\mathrm{Sm}$ and $\mathrm{Th}$ ) results in an increase of the ferromagnetic ordering temperature $T_{c}$ owing to an increase of the Fe-Fe distances and therefore of the Fe-Fe magnetic interactions [1-4]. C atoms are accommodated exclusively in octahedral $\mathrm{R}_{2} \mathrm{Fe}_{4}$ sites whereas $\mathrm{H}$ atoms can be found in both tetrahedral $\mathrm{R}_{2} \mathrm{Fe}_{2}$ sites and remaining $\mathrm{R}_{2} \mathrm{Fe}_{4}$ octahedral sites. Likewise, a substantial increase in the Curie temperature is observed in the carbide-hydride synthesized from the $\operatorname{Pr}_{3}(\mathrm{Fe}, \mathrm{Ti})_{29}$ compound due to volume cell expansion [5]. Simultaneous insertion of $\mathrm{C}$ and $\mathrm{H}$ atoms has also been investigated in the well-studied magnetocaloric phase $\mathrm{La}(\mathrm{Fe}, \mathrm{Si})_{13}$ [6-9]. Both $\mathrm{C}$ and $\mathrm{H}$ addition leads to an increase of $\mathrm{T}_{\mathrm{c}}$ to adjust it around room temperature for cooling applications. Additionally, $C$ insertion promotes the formation of the 1:13 phase and therefore reduces significantly the annealing time. Besides this, it also reduces the thermal and magnetic hysteresis loss and enhances the thermal stability of the hydride. In this carbidehydride both $\mathrm{H}$ and $\mathrm{C}$ atoms occupy octahedral vacant interstices $\mathrm{La}_{2}(\mathrm{Fe} / \mathrm{Si})_{4}$ [9], possibly in an off-centred position for hydrogen [10].

In this work we propose to investigate for the first time the insertion of two types of light elements in the family of the equiatomic intermetallics RTX ( $R=$ rare earth, $\mathrm{T}=$ transition metal, $X=p$ element). More specifically, we examine the incorporation of carbon and hydrogen atoms in the CeScSi-type compound $\mathrm{NdScSi}$. This structure consists in $\mathrm{Nd}_{2}$ layers made of empty edge-sharing $\mathrm{Nd}_{4}$ tetrahedra alternating with $\mathrm{Sc}_{2} \mathrm{Si}_{2}$ layers along the c-axis. This structure contains $\mathrm{Nd}_{4}$ tetrahedral interstices and $\mathrm{Nd}_{2} \mathrm{Sc}_{4}$ or $\mathrm{Si}_{2} \mathrm{Sc}_{4}$ octahedral empty cavities. $\mathrm{H}$ atoms are known to be able to fill the rare earth tetrahedron [11-16] as well as the $\mathrm{Nd}_{2} \mathrm{Sc}_{4}$ octahedron in some compounds like NdScSi or CeTiGe $[14,16]$. More precisely, the $\mathrm{H}$ atom in this second site is slightly shifted from the centre of the octahedron and thus occupies a $\mathrm{NdSC}_{4}$ square-based pyramidal site. Very recently, we have also demonstrated for NdScSi that it is possible to form the solid solution $\mathrm{NdScSiC}_{x}(0.25 \leq \mathrm{x} \leq 0.5)$ with carbon atoms occupying the vacant $\mathrm{Nd}_{2} \mathrm{Sc}_{4}$ octahedra [17]. As the $\mathrm{Nd}_{4}$ tetrahedra remain vacant in the carbide, one can consider to fill them with hydrogen. This step is, however, challenging since carbon insertion in the CeScSi-type intermetallic induces the opposite change in the unit cell to that seen during hydrogenation. Namely, the $a$ parameter increases while the $c$ parameter decreases. This stems from an expansion of the $\mathrm{Sc}_{4}$ square planes in the $\mathrm{Nd}_{2} \mathrm{Sc}_{4}$ octahedra to accommodate the carbon atoms with a simultaneous movement of the neodymium atoms closer to the Sc square planes driven by the establishment of a strong $\mathrm{Nd}-\mathrm{C}$ covalent bonding.

Carbon insertion in NdScSi preserves a ferromagnetic state but causes a substantial reduction in the Curie temperature from 171 to $50 \mathrm{~K}$ [17]. Density Functional Theory (DFT) calculations performed on $\mathrm{NdScSiC}_{0.5}$ point out that the $\mathrm{T}_{c}$ decreases owing to the loss of Nd-Sc spinpolarized interactions, reducing the magnetic coupling between the $\mathrm{Nd}$ atoms layers. The effect of hydrogenation on $\mathrm{NdScSi}$ is more striking since the magnetic ordering almost vanishes (only a magnetic anomaly whose nature remains unclear is evidenced at $4 \mathrm{~K}$ ) [14]. 
Such vanishing of the magnetic ordering temperature is usually noted through hydrogenation of the CeScSi-type intermetallic, as for GdTiGe, GdScGe or CeScX (X $=\mathrm{Si}, \mathrm{Ge})[11,12,15]$. So far, the only exception to that trend is the hydrogenation of the non-magnetic Kondo germanide CeTiGe that yields the onset of a magnetic order at $3.5 \mathrm{~K}$ [16]. These opposite results on hydrogen versus carbon insertion in $\mathrm{NdScSi}$ raises the question of the effect of a combined insertion of $\mathrm{C}$ and $\mathrm{H}$ on its magnetic properties.

Therefore, in this paper, we present the results on the synthesis of a carbide-hydride phase starting from the $\mathrm{NdScSiC}_{0.5}$ carbide and we discuss the effect of hydrogenation on the structural and magnetic properties changes of the parent phase.

\section{Experimental details}

The initial carbide $\mathrm{NdScSiC}_{0.5}$ was prepared using the method described previously [17]. Hydrogen absorption experiments were performed using the apparatus formerly described [14], however the conditions described there showed no evidence of hydrogen insertion. Therefore, more extreme conditions had to be used and the carbide-hydride was obtained at $450{ }^{\circ} \mathrm{C}$ and 40 bars of $\mathrm{H}_{2}$ pressure for 24 hours. After hydrogenation, the sample, which was stable in air, had noticeably decrepitated and the shiny metallic lustre was replaced by a dull grey colour.

Routine powder X-ray diffraction (XRD) was performed with the use of a PANalytical X'pert Pro diffractometer ( $\mathrm{Cu}-\mathrm{K}_{\alpha}$ radiation) for the phase identification and structural characterisation. X-ray powder data for Rietveld analysis were collected at room temperature using a PANalytical X'pert Pro diffractometer working with the $\mathrm{Cu}-\mathrm{K} \alpha_{1}(1.54051 \AA$ A) radiation in the range $10 \leq 2 \theta \leq 130^{\circ}$ and a step size of $0.008^{\circ}$. The powders used were ground and sieved to have particle sizes of less than $45 \mu \mathrm{m}$.

Magnetization measurements were performed using a superconducting quantum interference device (SQUID) magnetometer (Quantum Design MPMS-7XL) in the temperature range $2-300 \mathrm{~K}$ and in fields up to $7 \mathrm{~T}$. Specific heat measurements were done on a cold pressed pellet on a Quantum Design PPMS device using a standard relaxation method.

High resolution neutron diffraction was carried out on the $\mathrm{NdScSiC}_{0.5} \mathrm{H}_{\mathrm{x}}$ system on the D2B diffractometer at the ILL in Grenoble, France, with a wavelength $\lambda=1.59465 \AA$. For the study of the magnetic structure at low temperature, neutron diffraction patterns were collected on the D1B beamline at the ILL with $\lambda=2.52 \AA$. Rietveld refinements were carried out using the Fullprof program package [18]. 


\section{Results and discussion}

\subsection{Crystallographic properties}

\subsubsection{X-ray diffraction of $\mathrm{NdScSiC}_{0.5} \mathrm{H}_{x}$}

After the hydrogenation was carried out, the sample was crushed and powder X-ray diffraction (XRD) was performed to determine if any change in the unit cell parameters could be observed. The sample had noticeably decrepitated, being softer and easier to grind than the initial carbide material. Figure 1 shows a comparison of the powder XRD patterns of the samples with nominal composition $\mathrm{NdScSiC}_{0.5}$ before and after hydrogenation. A small change in the unit cell parameters can be observed by considering, for example, the $(00 /)$ and $(h k 0)$ peaks of the $\mathrm{NdScSiC}_{0.5}$ sample indexed considering the space group $14 / \mathrm{mmm}$. The $a$ parameter changes from $4.4107(4) \AA$ to $4.3996(4) \AA(-0.25 \%)$ and the $c$ parameter from $15.389(1) \AA$ to $15.4612(3)(+0.47 \%) \AA$. This change in the unit cell parameters is consistent with the trend observed on filling of the tetrahedral sites as seen for the hydrides GdScGeH [15] and GdTiGeH [12] and provides a promising indication that hydrogen has indeed been inserted into $\mathrm{NdSCSiC}_{0.5}$. However, the relatively small change in the unit cell parameters, in comparison with the above-mentioned hydrides, suggests that these sites are not completely filled. Hydrogenation for longer than 24 hours showed no further change in the unit cell parameters, indicating that no more hydrogen can be inserted under these conditions. The unit cell parameters for all of the compounds in the NdScSi family of insertion compounds (pristine, hydride, carbide and carbide-hydride) are gathered in Table 1. Due to the fragility of the samples, attempts to isolate a useable single-crystal for X-ray diffraction were unsuccessful. Structural characterisation was therefore carried out using neutron powder diffraction methods described below.
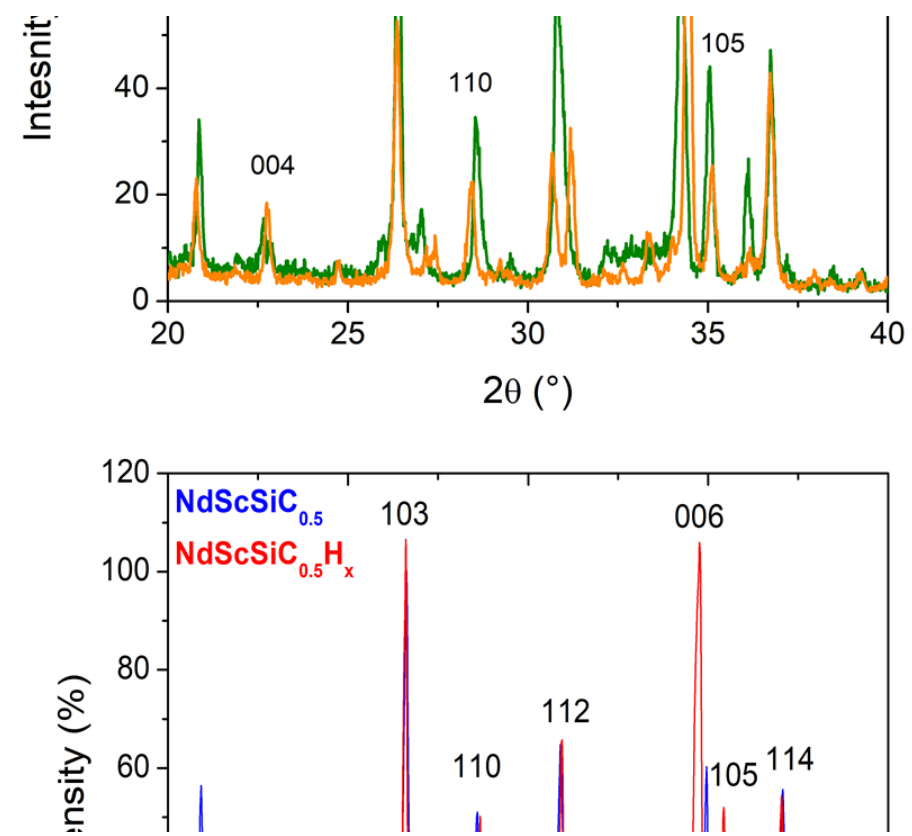

Figure 1. X-ray diffraction patterns for $\mathrm{NdScSiC}_{0.5}$ and $\mathrm{NdScSiC}_{0.5} \mathrm{H}_{\mathrm{x}}$ indexed with the space group $14 / \mathrm{mmm}$. 
Table 1. Unit cell parameters of $\mathrm{NdScSi}, \mathrm{NdScSiH}_{1.5}, \mathrm{NdScSiC}_{0.5}$ and $\mathrm{NdScSiC}_{0.5} \mathrm{H}_{\mathrm{x}}$ phases from refinement of powder XRD data.

\begin{tabular}{llllll}
\hline System & $\boldsymbol{a}(\AA)$ & $\boldsymbol{c}(\AA)$ & $\mathbf{V}\left(\AA^{3}\right)$ & $c / a$ & Reference \\
\hline $\mathrm{NdScSi}$ & $4.2894(6)$ & $15.705(3)$ & 288.956 & 3.661 & {$[14]$} \\
$\mathrm{NdScSiH}_{1.5}$ & $4.221(1)$ & $16.928(2)$ & 301.603 & 4.010 & {$[14]$} \\
$\mathrm{NdScSiC}_{0.5}$ & $4.4107(4)$ & $15.389(1)$ & 299.381 & 3.489 & This work \\
$\mathrm{NdSC}_{0.92(1)} \mathrm{SiC}_{0.5} \mathrm{H}_{0.21(1)}$ & $4.3996(3)$ & $15.4612(3)$ & 299.274 & 3.514 & This work \\
\hline
\end{tabular}

\subsubsection{High Resolution Neutron Powder diffraction on $\mathrm{NdScSiC}_{0.5} \mathrm{H}_{x}$}

In order to determine the exact crystallographic location and occupancy of the hydrogen atoms in the new $\mathrm{NdSCSiC}_{0.5} \mathrm{H}_{x}$ structure, high resolution neutron diffraction data was collected on the D2B diffractometer at the ILL. Initial Rietveld refinement of the neutron diffraction data was carried out starting from the crystal structure of $\mathrm{NdScSiC}_{0.5}$ without including hydrogen in the structural model. Once the refinement had converged, Fourier difference analysis between the observed and calculated data was performed to determine if there was any residual nuclear density. Figure 2(a) shows the Fourier difference map in the $z$ $=1 / 4$ cross-section before the inclusion of hydrogen. It shows clearly a steep minimum in the nuclear density in the $(01 / 21 / 4)$ position, i.e. inside the $\mathrm{Nd}_{4}$ tetrahedral sites. This suggests the presence of $H$ atoms which have a negative coherent neutron scattering length $\left(b_{c}(H)=-\right.$ $3.74 \mathrm{fm})[19]$. The residual nuclear density in the $\left(0 \frac{1}{2} 1 / 4\right)$ site is not negative however, which suggests that the site is only partially filled, in agreement with the small change in the unit cell parameters observed.

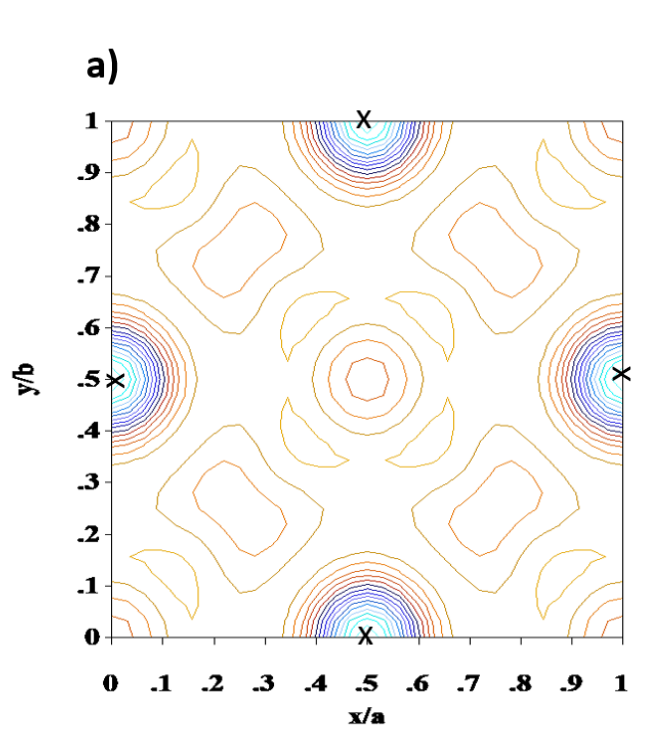

$$
z=0.25
$$

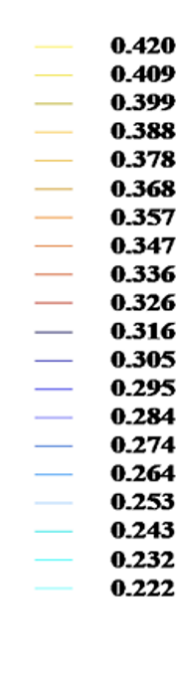

b)

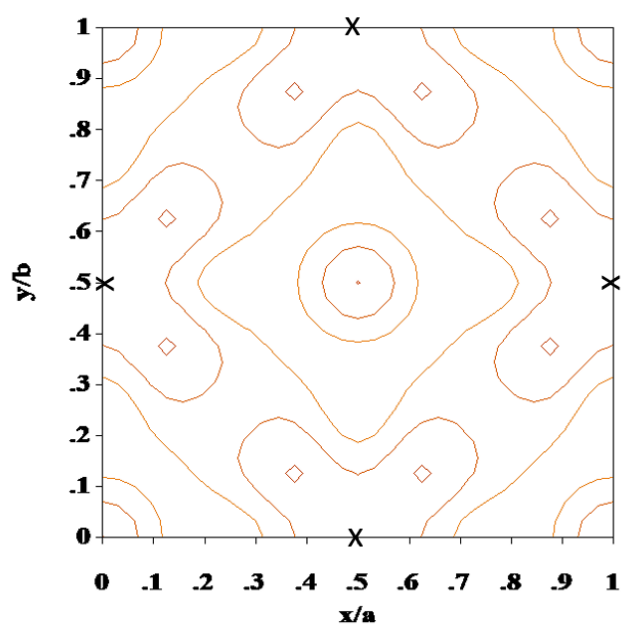

Figure 2. Fourier difference map from the nuclear structure refinement of $\mathrm{NdSc} \mathrm{C}_{0.92(1)} \mathrm{SiC}_{0.5} \mathrm{H}_{0.21(1)}$ before (a) and after (b) the inclusion of $H$ atoms. Images shown are for $z=0.25$. The centres of the tetrahedral sites are marked with a cross. 
Figure 2 (b) shows the Fourier difference map of the refinement after a hydrogen atom was added to the $(0,1 / 2,1 / 4)$ site with a refined occupancy of $21 \%$. It clearly indicates that the nuclear density is perfectly described for this site. Rietveld refinement of the neutron diffraction data over the whole angular range $\left(5-150^{\circ}\right)$ for $\mathrm{NdSC}_{0.92(1)} \mathrm{SiC}_{0.5} \mathrm{H}_{0.21(1)}$ can be seen in Figure 3. The only detectable secondary phase is $\mathrm{Sc}_{2} \mathrm{OC}$ which is present in all of the carbide samples. The parameters of this refinement and the refined crystal structure are given in Table 2 and Table 3 respectively. A representation of the refined nuclear structure is depicted in Figure 4. The atomic isotropic displacement parameters $B_{\text {iso }}$ were constrained to be equal, except that of $\mathrm{H}$ atom, to refine the occupancies. This is also consistent with the values determined on the $\mathrm{Nd}_{1.02} \mathrm{Sc}_{0.98} \mathrm{SiC}_{0.5}$ single-crystal [17]. The refinement confirms that the $\mathrm{Nd}_{2} \mathrm{Sc}_{4}$ octahedra are filled by carbon atoms only and that hydrogen does not partially replace the carbon on this site. Additionally, the refinement is significantly improved by considering a sub-stoichiometry in the scandium site occupancy with a value of 0.92(1). This is similar to what Ritter et al. describe in their neutron diffraction experiments on CeScSi and LaScSi, with an occupancy of the Sc sites of 0.912(5) and 0.924(4) respectively [20]. However, we can assume here that this sub-stoichiometry is likely over-estimated regarding the refinement obtained on $\mathrm{Nd}_{1.02} \mathrm{Sc}_{0.98} \mathrm{SiC}_{0.5}$ single-crystal. Finally, $\mathrm{NdScSiC} 0.5 \mathrm{H}_{0.21}$ adopts the $\mathrm{La}_{2} \mathrm{Fe}_{2} \mathrm{Se}_{2} \mathrm{O}_{3}$ structure type, as do the hydrides $\mathrm{NdScSiH}{ }_{1.5}, \mathrm{CeTiGeH}_{1.5}$ and $\mathrm{La}_{2} \mathrm{Ti}_{2} \mathrm{As}_{2} \mathrm{H}_{2.3}[14,16,21]$. This 2223 structure type generally appears in other mixed-anion systems like transition metal oxychalcogenides/oxypnictides (see e.g. [22-24]) or the oxyhydride $\mathrm{La}_{2} \mathrm{Cr}_{2} \mathrm{As}_{2} \mathrm{O}_{1.6} \mathrm{H}_{1.3}$ [25]. In this last example, hydrogen occupies preferentially the Wyckoff $2 b$ position while oxygen is mainly accommodated in the $4 d$ site.

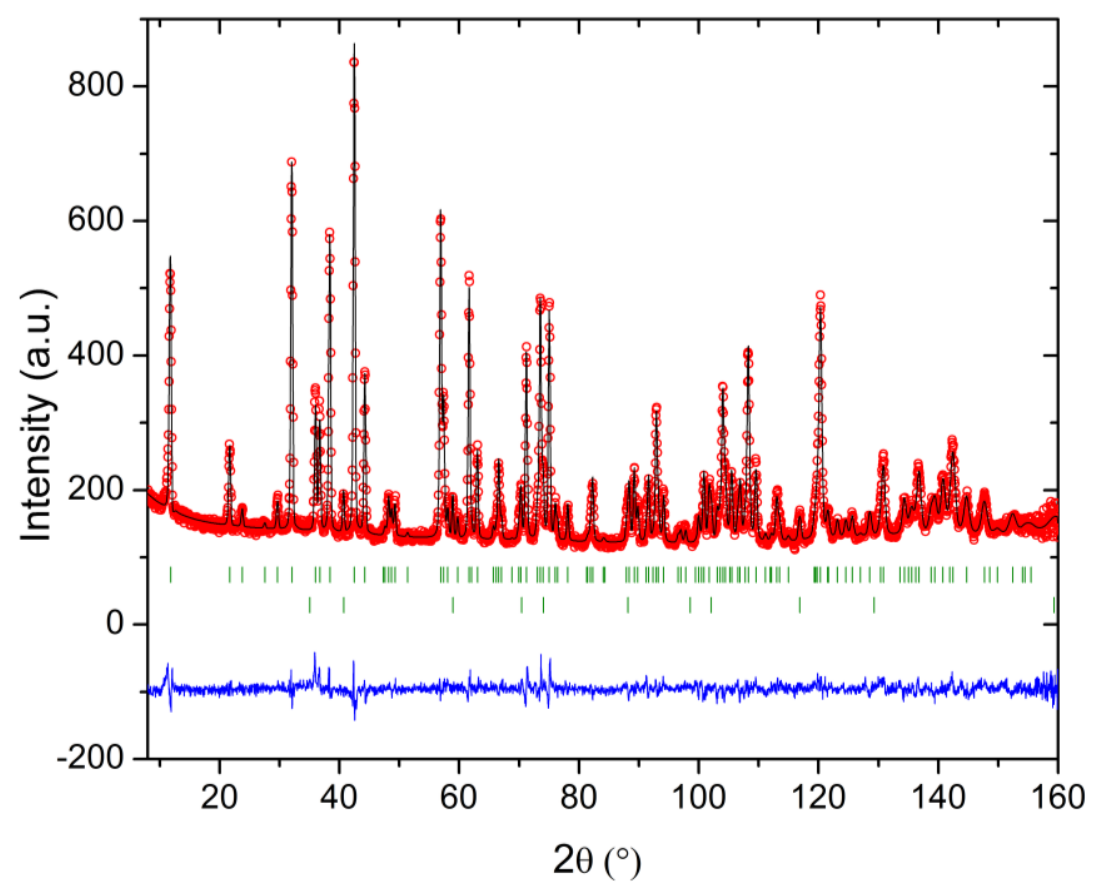

Figure 3. Refinement of the high-resolution neutron powder diffraction pattern collected at room temperature with $\lambda=1.5946 \AA$. The first and second rows of ticks correspond to the Bragg peak positions of the phases $\mathrm{NdSc}_{0.92(1)} \mathrm{SiC}_{0.5} \mathrm{H}_{0.21(1)}$ and $\mathrm{Sc}_{2} \mathrm{OC}$ respectively. 
Table 2. Parameters of the nuclear structure refinement of $\mathrm{NdSC}_{0.92(1)} \mathrm{SiC}_{0.5} \mathrm{H}_{0.21(1)}$.

\begin{tabular}{lllllll}
\hline Phase & $\mathrm{a}(\AA)$ & $c(\AA)$ & $\begin{array}{l}\text { Amount } \\
(\mathbf{W t . \% )}\end{array}$ & $\begin{array}{l}\text { R-Bragg } \\
(\%)\end{array}$ & $\mathbf{R}_{\mathrm{p}}(\%)$ & $\mathbf{R}_{\mathrm{wp}}(\%)$ \\
\hline $\mathrm{NdSC}_{0.92(1)} \mathrm{SiC}_{0.5} \mathrm{H}_{0.21(1)}$ & $\begin{array}{l}4.39986(4) \\
\mathrm{Sc}_{2} \mathrm{OC}\end{array}$ & $15.4657(3)$ & $99(1)$ & 4.8 & 15.4 & 13.1 \\
\hline
\end{tabular}

Table 3. The refined crystal structure of $\mathrm{NdSc}_{0.92(1)} \mathrm{SiC}_{0.48(1)} \mathrm{H}_{0.21(1)}$.

\begin{tabular}{lllllll}
\hline Atom & $\begin{array}{l}\text { Wyckoff } \\
\text { position }\end{array}$ & $\mathbf{x}$ & $\mathbf{y}$ & $\mathbf{z}$ & $\mathbf{B}_{\text {iso }}$ & Occ. \\
\hline Nd & $4 e$ & 0 & 0 & $0.3324(1)$ & $0.53(2)$ & 1 \\
Sc & $4 c$ & 0 & 0.5 & 0 & $0.53(2)$ & $0.92(1)$ \\
Si & $4 e$ & 0 & 0 & $0.1266(2)$ & $0.53(2)$ & 1 \\
C & $2 b$ & 0 & 0 & 0.5 & $0.53(2)$ & $0.48(1)$ \\
H1 & $4 d$ & 0 & 0.5 & 0.25 & $1.7(4)$ & $0.21(1)$ \\
\hline
\end{tabular}

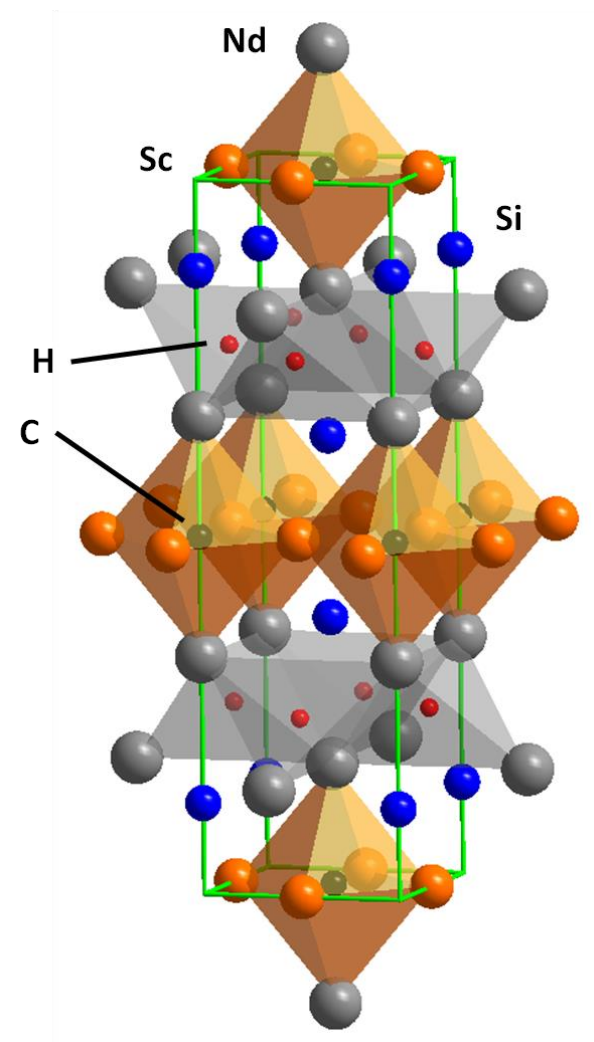

Figure 4. The crystal structure of $\mathrm{NdSc}_{0.92(1)} \mathrm{SiC}_{0.5} \mathrm{H}_{0.21(1)}$ emphasising the octahedral and tetrahedral sites for carbon and hydrogen atoms respectively. 
As expected, the hydrogenation of $\mathrm{NdScSiC}_{0.5}$ changes the interatomic distances in the same way that hydrogenation of the pristine $\mathrm{NdScSi}$ does. However, the difference in the interatomic distances between the carbide-hydride and the parent carbide is small since the filling of the hydrogen site is low. The interatomic distances for the entire $\mathrm{NdScSiC}_{x} \mathrm{H}_{\mathrm{y}}$ system $(x=0$ and $0.5 ; y=0,0.21$ and 1.5) are summarised in Table 4 and the internal tetrahedral angles $\mathrm{Nd}$ - $\mathrm{Td}$-Nd formed by two $\mathrm{Nd}$ atoms and the tetrahedral centre $\mathrm{Td}$ are listed in Table 5. Regarding the $\mathrm{Nd}_{4}$ tetrahedra, both $\mathrm{Nd}-\mathrm{Nd}$ distances decrease with the insertion of hydrogen, consistent with a very slight contraction of the tetrahedra. Consequently, the distance $\mathrm{Nd}$ $\mathrm{H} 1 / T d$ between the $\mathrm{Nd}$ atoms and the tetrahedral centre $T d$ is reduced, from $2.551 \AA$ in the carbide to $2.542 \AA$ in the carbide-hydride. However, this last distance remains significantly larger than $\mathrm{d}_{\mathrm{Nd}-\mathrm{H} 1}=2.388 \AA$ in the $\mathrm{NdScSiH}_{1.5}$ hydride, value that is close to that in the binary $\mathrm{NdH}_{2}$ of $2.368 \AA$ [26]. An opposite evolution of the $\mathrm{d}_{\mathrm{Nd}-\mathrm{H} 1 / \mathrm{Td}}$ distances is noted through carbon insertion. The change of two tetrahedral angles $\mathrm{Nd}-\mathrm{Td}$ - $\mathrm{Nd}$ after the hydrogenation of $\mathrm{NdScSiC}_{0.5}$ is too small to be significant, but the general tendency is a regularisation of the tetrahedra with $C$ insertion with both tetrahedral angles getting closer to the ideal value of $109.5^{\circ}$ (Table 5). On the contrary, hydrogenation induces an opposite trend with angles moving further from ideality. To sum up, carbon insertion causes an expansion and a regularisation of the $\mathrm{Nd}_{4}$ tetrahedra while hydrogenation produces an opposite effect.

Regarding the $\mathrm{Nd}_{2} \mathrm{Sc}_{4}$ octahedra, we observe an increase in the $\mathrm{Nd}-\mathrm{C}$ carbon distances from 2.567 to $2.592 \AA$ during the formation of the carbide-hydride combined with a slight decrease in the Sc-C distances from 2.208 to $2.200 \AA$. In fact the $\mathrm{d}_{\mathrm{Nd}-\mathrm{C} / \mathrm{O} \text { h }}$ distance between the octahedral centre and apical Nd atom increases a lot during hydrogenation (from $2.772 \AA$ in $\mathrm{NdScSi}$ to $3.115 \AA$ in $\mathrm{NdScSi}_{1.5}$ ) because of the contraction of the $\mathrm{Nd}_{4}$ tetrahedra while it strongly decreases with $\mathrm{C}$ insertion $\left(2.567 \AA\right.$ in $\left.\mathrm{NdScSiC}_{0.5}\right)$ owing to the $\mathrm{Nd}-\mathrm{C}$ bonding formation. Therefore, it is likely that the strong bonding between the carbon and $\mathrm{Nd}$ atoms resists the contraction of the tetrahedral sites upon hydrogenation of the carbide and thus prevents full occupancy in the carbide-hydride. In other words, the low hydrogen site occupancy can be explained by considering the antagonistic effect of filling the tetrahedral and octahedral sites by $\mathrm{H}$ and $\mathrm{C}$ atoms respectively. 
Table 4. The interatomic distances of the $\mathrm{NdScSiC}_{\mathrm{x}} \mathrm{H}_{\mathrm{y}}$ family of intermetallic compounds ( $\mathrm{NdScSi}$, $\mathrm{NdScSiH}_{1.5}, \mathrm{NdScSiC}_{0.5}, \mathrm{NdScSiC} \mathrm{C}_{0.5} \mathrm{H}_{0.21}$ ) calculated from refinement of room temperature XRD data. The $\mathrm{Nd}-\mathrm{Td}$ and $\mathrm{Nd}-\mathrm{O} h$ distances given are the distances to the empty tetrahedral and octahedral site respectively where appropriate.

\begin{tabular}{|c|c|c|c|c|}
\hline \multirow[b]{2}{*}{ Atom } & \multicolumn{4}{|l|}{$d(\AA)$} \\
\hline & $\mathrm{NdScSi}[14]$ & $\mathrm{NdScSiH}_{1.5}[14]^{\mathrm{c}}$ & $\mathrm{NdScSiC}_{0.5}[17]$ & $\mathrm{NdSC}_{0.92} \mathrm{SiC}_{0.5} \mathrm{H}_{0.21}$ \\
\hline $\mathrm{Nd}-\mathrm{Nd}^{\mathrm{a}}$ & 3.811 & $3.73(1)$ & 4.035 & $4.021(1)$ \\
\hline $\mathrm{Nd}-\mathrm{Nd}{ }^{b}$ & 4.289 & $4.221(1)$ & 4.416 & $4.3996(3)$ \\
\hline $\mathrm{Nd}-\mathrm{Sc}$ & 3.505 & $3.76(1)$ & 3.386 & $3.399(1)$ \\
\hline $\mathrm{Nd}-\mathrm{Si}$ & 3.148 & $3.243(9)$ & 3.147 & $3.1730(7)$ \\
\hline $\mathrm{Nd}-\mathrm{Si}^{\prime}$ & 3.151 & $3.50(2)$ & 3.178 & $3.182(4)$ \\
\hline $\mathrm{Nd}-\mathrm{C} / \mathrm{Oh}$ & 2.772 & 3.115 & 2.567 & $2.592(2)$ \\
\hline $\mathrm{Nd}-\mathrm{H} 1 / T d$ & 2.435 & $2.388(8)$ & 2.551 & $2.542(1)$ \\
\hline $\mathrm{Nd}-\mathrm{H} 2$ & - & $2.81(2)$ & - & - \\
\hline Sc-Sc & 3.033 & $2.985(1)$ & 3.122 & $3.1109(1)$ \\
\hline Sc-Si & 2.885 & $2.80(1)$ & 2.963 & $2.945(2)$ \\
\hline $\mathrm{Sc}-\mathrm{C} / \mathrm{Oh}$ & 2.145 & 2.110 & 2.208 & $2.1998(2)$ \\
\hline $\mathrm{Sc}-\mathrm{H} 1$ & - & $4.232(1)$ & - & $3.8649(1)$ \\
\hline $\mathrm{Sc}-\mathrm{H} 2$ & - & $2.132(1)$ & - & - \\
\hline $\mathrm{Si}-\mathrm{C} / \mathrm{Oh}$ & 3.595 & & 3.695 & $3.676(2)$ \\
\hline $\mathrm{Si}-\mathrm{H} 1$ & - & $3.19(1)$ & - & $2.912(2)$ \\
\hline $\mathrm{Si}-\mathrm{H} 2$ & - & $3.359(8)$ & - & - \\
\hline \multicolumn{3}{|c|}{$\begin{array}{l}\text { a distance between adjacent layers } \\
\text { b distance within the same layer } \\
\text { c distances calculated with the cell } \\
\text { parameters determined from XRD and } \\
\text { atomic positions from NPD }\end{array}$} & \multicolumn{2}{|c|}{$\begin{array}{l}T d \text { corresponds to the centre of the } \\
\mathrm{Nd}_{4} \text { tetrahedron with coordinates } \\
(0,1 / 2,1 / 4) \\
\text { Oh corresponds to the centre of the } \\
\mathrm{Sc}_{4} \mathrm{Nd}_{2} \text { octahedron with } \\
\text { coordinates }(0,0,0.5)\end{array}$} \\
\hline
\end{tabular}

Table 5. Evolution of the internal tetrahedral angles of $\mathrm{NdScSi}$ during light element insertion.

\begin{tabular}{|c|c|c|c|c|}
\hline & \multicolumn{4}{|c|}{ Angle $\left({ }^{\circ}\right)$} \\
\hline & $\mathrm{NdScSi}$ & $\mathrm{NdScSiH}_{1.5}$ & $\mathrm{NdScSiC}_{0.5}$ & $\mathrm{NdSC}_{0.92} \mathrm{SiC}_{0.5} \mathrm{H}_{0.21}$ \\
\hline \multirow[t]{2}{*}{$\mathrm{Nd}-\mathrm{Td}-\mathrm{Nd}$} & 103.0 & 102.6 & 104.5 & 104.5 \\
\hline & 123.4 & 124.2 & 119.9 & 119.8 \\
\hline
\end{tabular}

\subsection{Magnetic properties}

Hydrogen insertion into $\mathrm{NdScSi}$ led to a sharp reduction in the magnetic ordering temperature from $171 \mathrm{~K}$ to $4 \mathrm{~K}$ owing to the weakening of the $\mathrm{Nd}$-Sc interaction (mediating the $\mathrm{Nd}-\mathrm{Nd}$ magnetic interactions) through the establishment of competing $\mathrm{Nd}-\mathrm{H} 1$ and $\mathrm{Sc}-\mathrm{H} 2$ covalent bondings. In contrast, carbon insertion in NdScSi maintains a ferromagnetic order since $\mathrm{C}$ and still Sc mediate the magnetic interactions between $\mathrm{Nd}$ double layers. In this context, the simultaneous effect of $\mathrm{C}$ and $\mathrm{H}$ insertion in $\mathrm{NdScSi}$ is interesting to examine. 


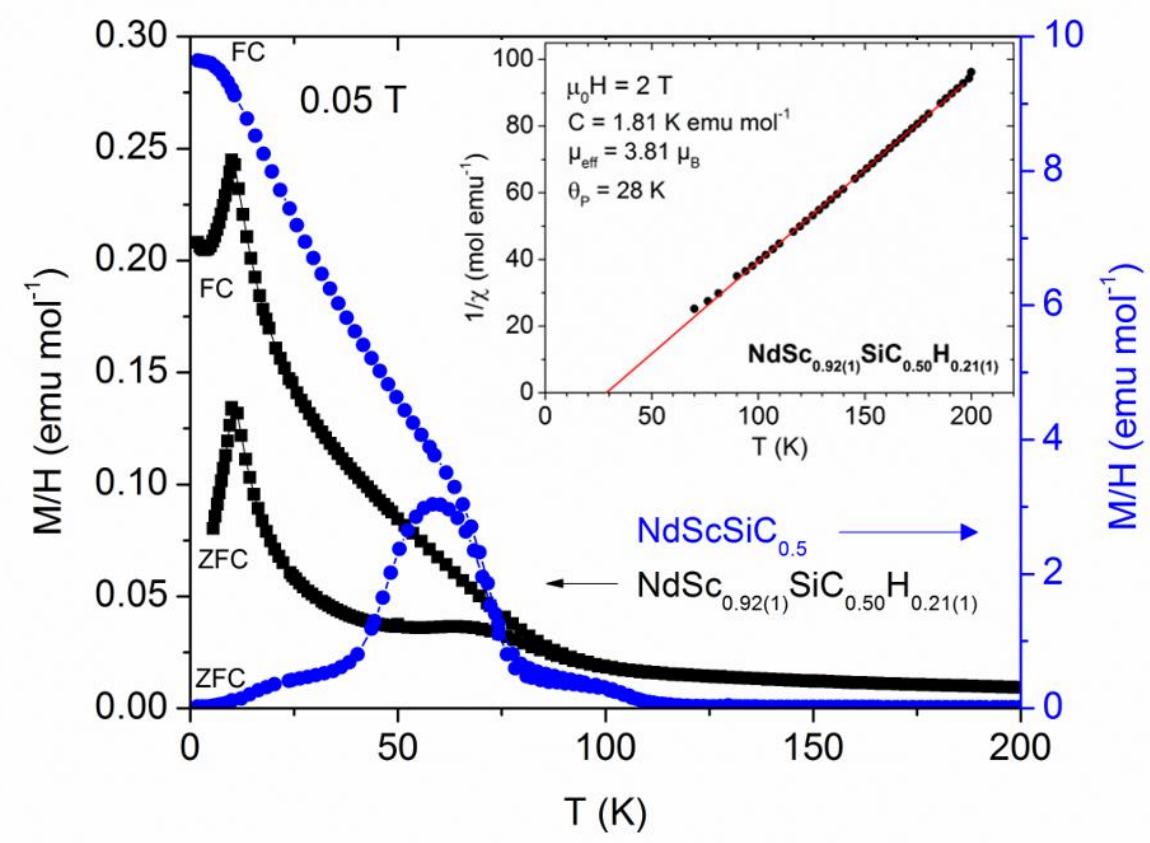

Figure 5. ZFC-FC magnetisation curves for $\mathrm{NdScSiC}_{0.5}$ and $\mathrm{NdScSiC}_{0.5} \mathrm{H}_{0.21}$ in a field of $0.05 \mathrm{~T}$. Inset: inverse magnetic susceptibility fitted using the Curie-Weiss type law.

Figure 5 shows the zero-field-cooled (ZFC) and field-cooled (FC) magnetisation curves for the $\mathrm{NdScSiC} 0.5 \mathrm{H}_{0.21}$ sample and its parent carbide measured in a field of $0.05 \mathrm{~T}$. One notice a Curie temperature $T_{c}$ around $70 \mathrm{~K}$ for the parent carbide. The ordering temperature in the solid solution $\mathrm{NdScSiC}_{\mathrm{x}}$ is very sensitive to the carbon content and in this carbide we have a carbon content slightly below the nominal $x=0.5$ [17]. From lattice parameters and neutron Rietveld refinement one can estimate the average carbon content at $x=0.48(1)$, i.e. close to the target composition. The expected $T_{C}$ should be around $55-60 \mathrm{~K}$ for $\mathrm{x}=0.48(1)$ but the $T_{C}$ onset is observed around $\sim 70 \mathrm{~K}$ because there is some distribution of the $C$ content through the large neutron sample down to $x=0.42(1)$. From the ZFC-FC curves features and values, it is clear that the insertion of hydrogen induces a change in the type of magnetic order. A sharp peak at $10 \mathrm{~K}$ replaces the jump observed at around $T_{C}=70 \mathrm{~K}$ in the initial ferromagnetic carbide, indicating the onset of an antiferromagnetic order. A small shoulder is seen in the ZFC curve of the carbide-hydride around $70 \mathrm{~K}$ with a corresponding divergence between the ZFC and FC curves. We assign it to the presence of a ferromagnetic impurity phase, most likely a residue of the initial carbide that was not hydrogenated during the reaction. However, the secondary phase is not detectable on the XRD or neutron diffraction patterns to confirm this hypothesis because the amount is low and the peaks strongly overlap with those of the main phase owing to very close unit cell parameters.

As shown in the inverse of the susceptibility versus temperature plot (inset Figure 5), $\mathrm{NdScSiC}{ }_{0.5} \mathrm{H}_{0.21}$ is a Curie-Weiss paramagnet like $\mathrm{NdScSi}$ and $\mathrm{NdScSiC}_{0.5}$. The calculated effective magnetic moment of $3.81 \mu_{\mathrm{B}} \mathrm{Nd}^{-1}$ is slightly higher than, but close to, the value of $3.62 \mu_{\mathrm{B}} \mathrm{Nd}^{-1}$ expected from a Nd ${ }^{3+}$ system. Interestingly, the paramagnetic Curie temperature 
$\theta_{p}$ shows a positive value of $28 \mathrm{~K}$ suggesting that the predominant local interactions between $\mathrm{Nd}$ atoms are ferromagnetic albeit the magnetic order is antiferromagnetic.

The specific heat of $\mathrm{NdScSiC}_{0.5} \mathrm{H}_{0.21}$ (Figure 6) displays a lambda peak at $10 \mathrm{~K}$, confirming the Néel temperature assigned from the maximum of the peak in the ZFC-FC magnetisation curve of Figure 5 . The absence of anomaly around $70 \mathrm{~K}$ is coherent with the presence of a low amount of carbide residue and supports the assumption that this transition is not intrinsic to the carbide-hydride.

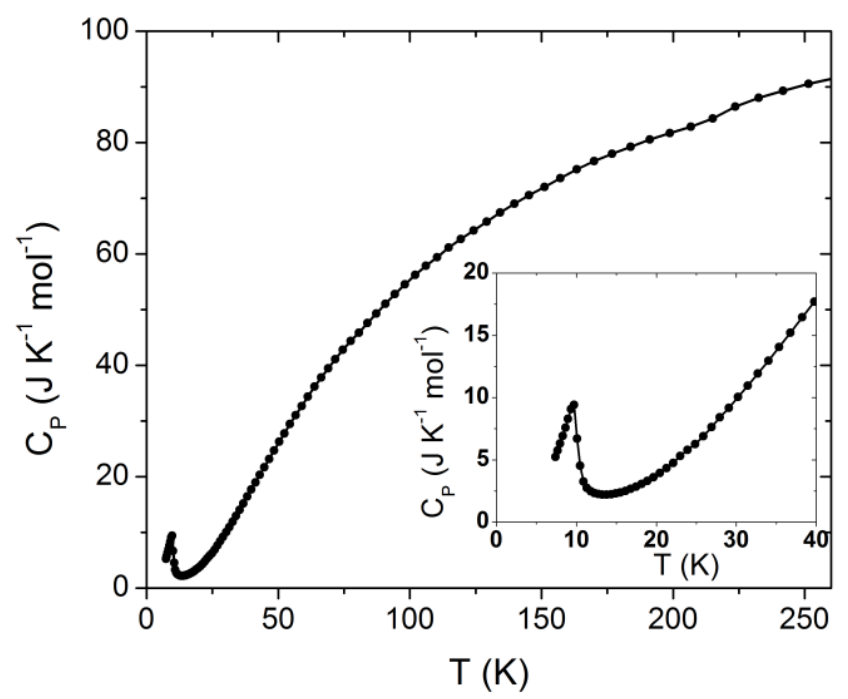

Figure 6. Specific heat at constant pressure of the $\mathrm{NdScSiC} \mathrm{C}_{0.5} \mathrm{H}_{0.21}$ system down to low temperatures. The inset shows a zoom of the low temperature part.

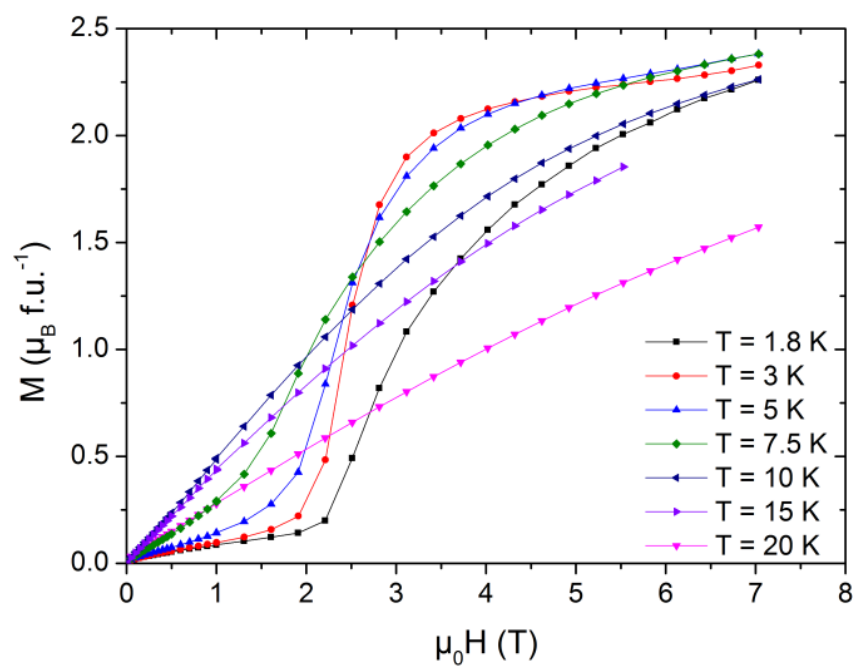

Figure 7. Isothermal magnetisation curves of $\mathrm{NdScSiC}_{0.5} \mathrm{H}_{0.21}$.

Figure 7 displays the isothermal magnetisation curves for the $\mathrm{NdScSiC}_{0.5} \mathrm{H}_{0.2}$ sample for the entire $0-7 \mathrm{~T}$ range. The curves above $T_{N}$ are almost linear, as expected for a 
paramagnetic state. Below $T_{N}$ the low field part of the curves is linear, confirming the antiferromagnetic order that was assigned from the ZFC-FC magnetisation measurements. Furthermore, we observe a metamagnetic transition at higher field. For example, the critical field (assigned from the point of inflection of the curves) is $\mu_{0} \mathrm{H}_{\mathrm{C}} \approx 2.5 \mathrm{~T}$ at $1.8 \mathrm{~K}$ and $1.5 \mathrm{~T}$ at $7.5 \mathrm{~K}$. At $7 \mathrm{~T}$ the curves show that the material is not fully saturated, but it is likely that the field-induced metamagnetic transition corresponds to a change from an antiferromagnetic to a ferromagnetic order.

To further investigate the metamagnetic transition, ZFC-FC measurements were performed at $4 \mathrm{~T}$ (Figure 8 ). The form of the $4 \mathrm{~T}$ curve suggests ferromagnetic rather than an antiferromagnetic ordering at this field. The Curie temperature, $T_{C}=7.4 \mathrm{~K}$, was assigned from the inflection point of the ZFC and FC curves. There is small deviation between the ZFC and FC curves below the Curie temperature as observed for the parent ferromagnetic carbide $\mathrm{NdScSiC}{ }_{0.5}$. This change to a ferromagnetic state is in good agreement with the positive CurieWeiss temperature indicating dominant ferromagnetic interactions and the occurrence of metamagnetism.

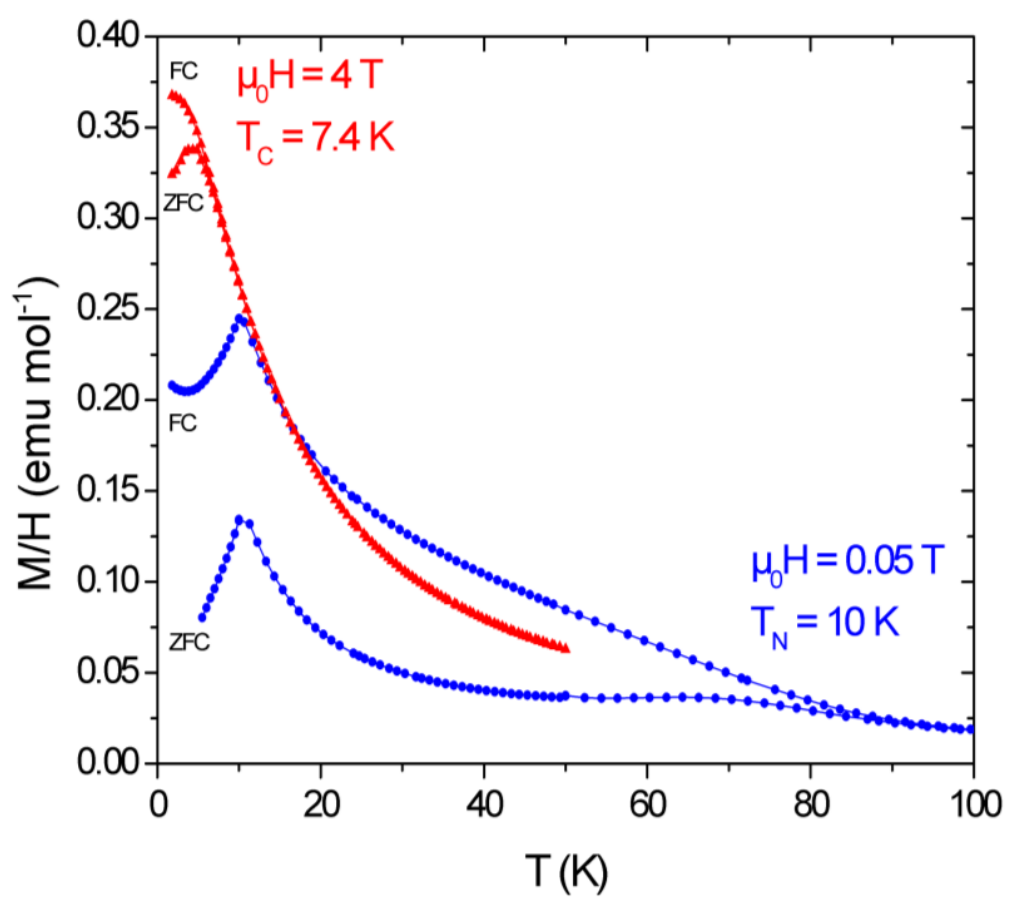

Figure 8. ZFC-FC magnetisation curves for $\mathrm{NdScSiC}_{0.5} \mathrm{H}_{0.21}$ at $0.05 \mathrm{~T}$ and $4 \mathrm{~T}$.

\subsection{Magnetic Structure of $\mathrm{NdScSiC}_{0.5} \mathrm{H}_{0.2}$}

The measurements of magnetisation and susceptibility reveal a change in the type of magnetic order of $\mathrm{NdScSiC}_{0.5}$ upon hydrogenation. The effect of the hydrogen insertion on the magnetic structure is therefore of significant interest. In order to further investigate this, neutron diffraction was performed on this sample. Diffraction patterns were collected during the cooling of this material from $100 \mathrm{~K}$ to $1.5 \mathrm{~K}$. No change in the intensity of the peaks is 
observed between $100 \mathrm{~K}$ and $11 \mathrm{~K}$, magnetic peaks appearing only below $11 \mathrm{~K}$. This is illustrated in Figure 9, showing the patterns collected at $11 \mathrm{~K}$ and at $1.5 \mathrm{~K}$ with the difference between the two. This is consistent with the ZFC-FC magnetisation and specific heat capacity curves used to assign the $T_{N}=10 \mathrm{~K}$ and this confirms that the magnetic anomaly at $70 \mathrm{~K}$ is not intrinsic to the carbide-hydride phase.

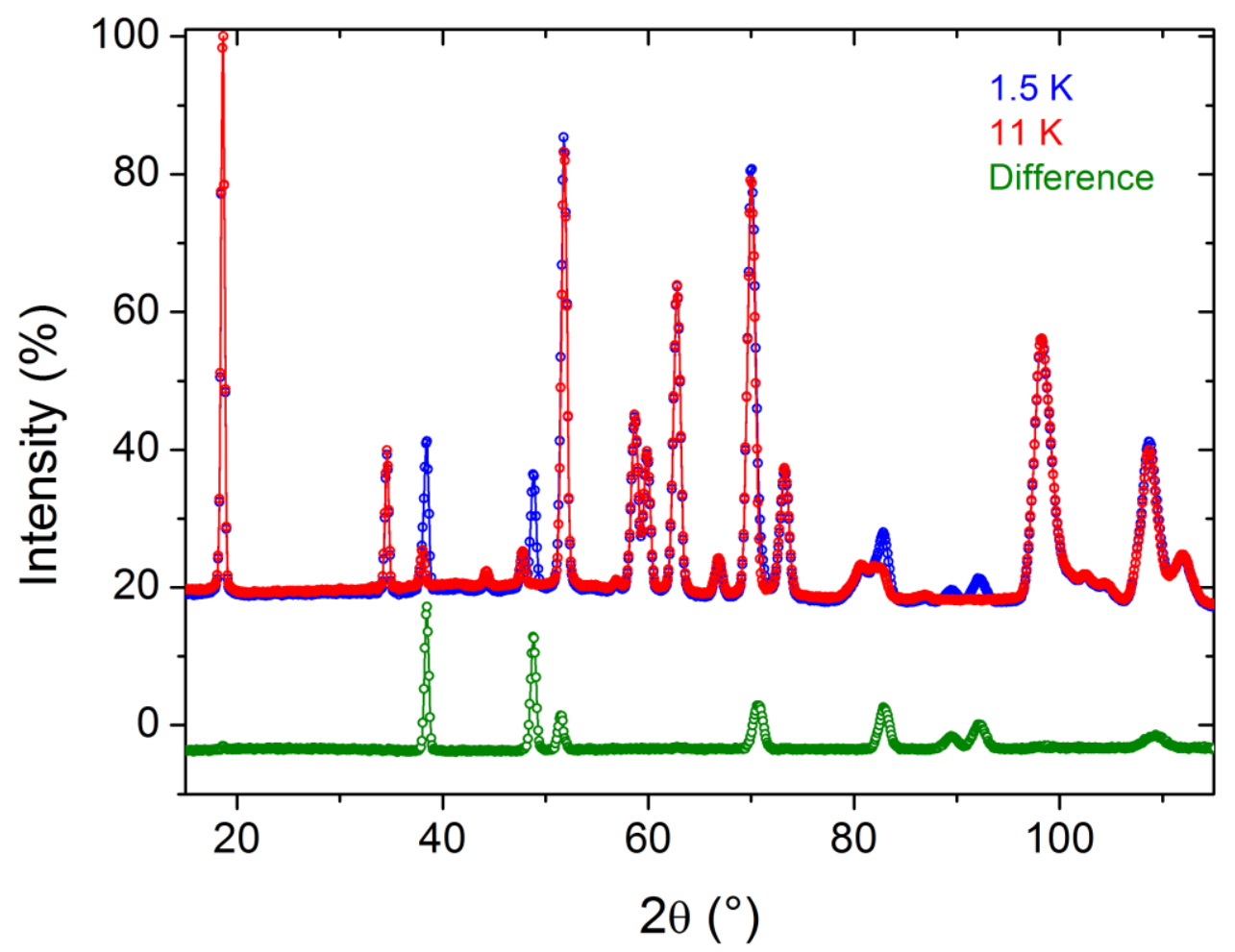

Figure 9. Neutron diffraction pattern of $\mathrm{NdScSiC}_{0.5} \mathrm{H}_{0.21}$ at 11 and $1.5 \mathrm{~K}$ with the difference pattern plotted below to illustrate the magnetic peaks.

The new magnetic peaks do not correspond with the positions of the nuclear peaks of the main phase but rather with reflections that are forbidden by symmetry in the $14 / \mathrm{mmm}$ space group of the crystal structure $(h+k+l=$ odd). This indicates that the nuclear and magnetic structures do not share the same symmetry. The difference pattern in Figure 9 was

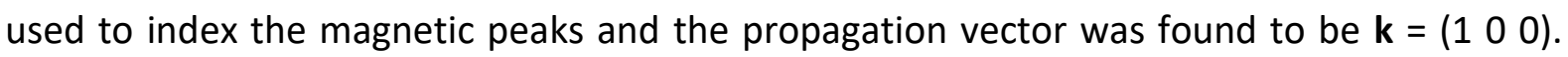
Thus the magnetic and crystal unit cells are the same size but with a loss of the centring in the magnetic structure. At $1.5 \mathrm{~K}$, the best model used to refine the neutron diffraction data is an antiferromagnetic structure consisting of $\mathrm{Nd}$ moments aligned along the $c$-axis in ferromagnetic double layers, stacked antiferromagnetically along the $c$-axis as illustrated in Figure 10 with that of the parent carbide for comparison. 

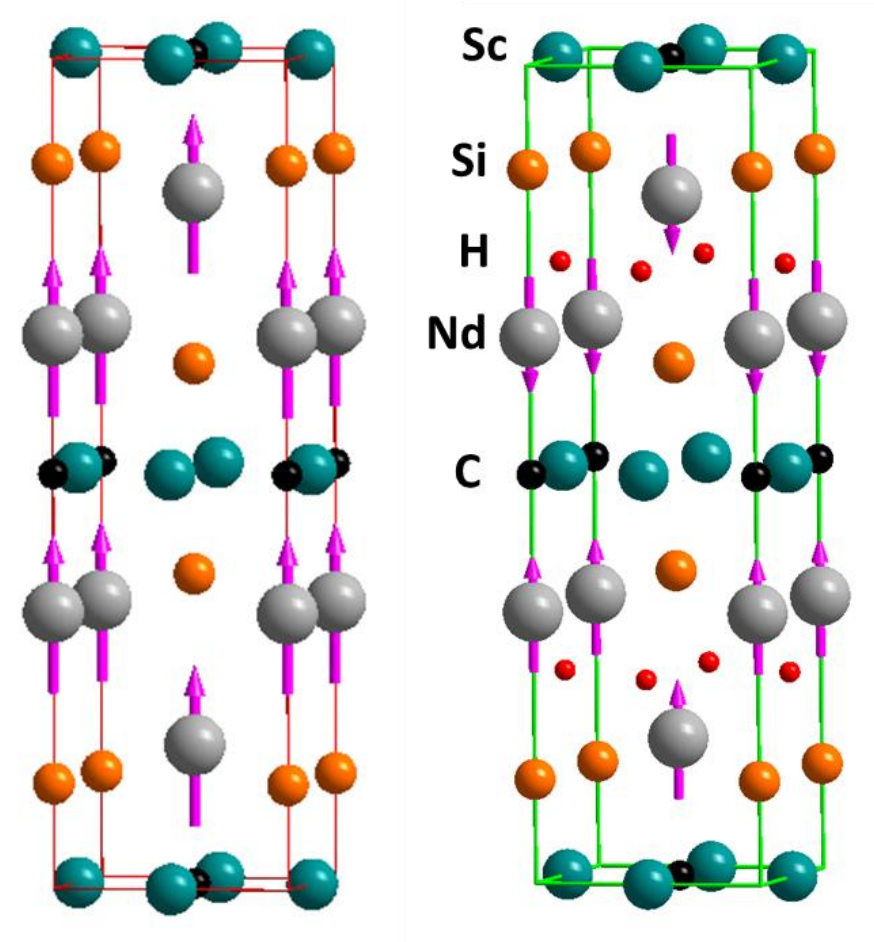

Figure 10. Magnetic structure of $\mathrm{NdScSiC}_{0.5}$ (left) and $\mathrm{NdScSiC}_{0.5} \mathrm{H}_{0.21}$ (right).

The fit of the experimental data using this model is depicted in Figure 11 and a summary of the refined structure parameters is given in Table 6. Therefore it appears that partial hydrogen insertion in $\mathrm{NdScSiC}_{0.5}$ modifies the magnetic interactions between the layers of $\mathrm{Nd}_{4}$ tetrahedra. The refined magnetic moment which is plotted against temperature in Figure 1 attains a value of $2.73(2) \mu_{B}$ at $1.8 \mathrm{~K}$. This is slightly higher than the moment of 2.4 $\mu_{B}$ seen in the $M(H)$ curves at $7 \mathrm{~T}$, as expected since the saturation magnetisation was not completely reached at this field. This confirms that the field induced metamagnetic transition corresponds to a change from an antiferromagnetic to a ferromagnetic state with a spin flip of one out of every two ferromagnetic double layers. This is coherent with the presence of predominant ferromagnetic interactions within the $\mathrm{Nd}_{4}$ layers compared to the antiferromagnetic ones between these layers, in agreement with a positive $\theta_{p}$ temperature.

The magnetic moment value is significantly below the expected value (gJ) of $3.27 \mu_{\mathrm{B}}$ for a trivalent $\mathrm{Nd}$ free ion and also smaller than the refined $\mathrm{Nd}$ magnetic moment of 3.09(4) $\mu_{\mathrm{B}}$ for the parent $\mathrm{NdScSiC} \mathrm{C}_{0.5}$ material. This reduction may stem from the creation of new $\mathrm{Nd}$ $\mathrm{H}$ bonding states or, most likely, from a modification of the crystal-electric field effect after hydrogenation. 


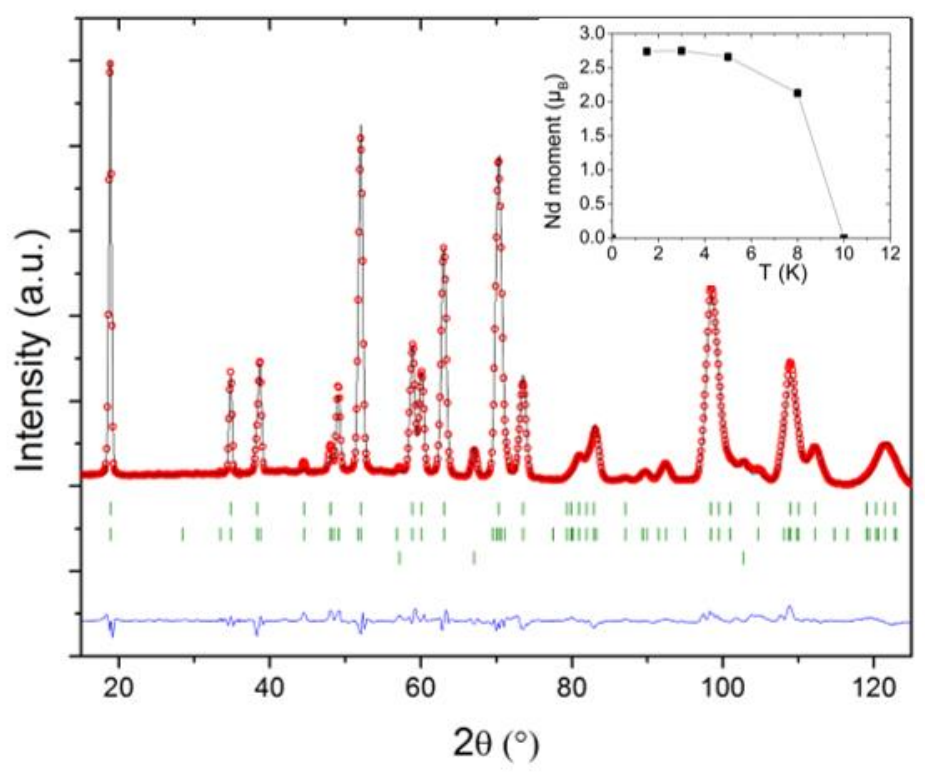

Figure 11. Refinement of the magnetic structure of $\mathrm{NdScSiC}_{0.5} \mathrm{H}_{0.21}$ at $1.5 \mathrm{~K}$. The first and second ticks rows correspond to the Bragg peak positions of the nuclear and magnetic phases $\mathrm{NdScSiC} 0.5 \mathrm{H}_{0.21}$ and the third one of the $\mathrm{Sc}_{2} \mathrm{OC}$ nuclear phase. The inset shows the evolution with temperature of the refined $\mathrm{Nd}$ magnetic moment.

Table 6. Summary of refined parameters from the refinement of the magnetic structure of $\mathrm{NdScSiC} \mathrm{C}_{0.5} \mathrm{H}_{0.21}$.

\begin{tabular}{llllllllll}
\hline $\mathrm{T}(\mathrm{K})$ & a $(\AA)$ & $c(\AA)$ & $z_{\mathrm{Nd}}$ & $\mathrm{Z}_{\mathrm{Si}}$ & $\begin{array}{l}\mathrm{Nd} \\
\text { moment } \\
\left(\mu_{\mathrm{B}}\right)\end{array}$ & $\begin{array}{l}\text { Nuclear } \\
\text { R-Bragg } \\
(\%)\end{array}$ & $\begin{array}{l}\text { Magnetic } \\
\text { R-Bragg } \\
(\%)\end{array}$ & $\begin{array}{l}\mathrm{R}_{\mathrm{p}} \\
(\%)\end{array}$ & $\begin{array}{l}\mathrm{R}_{\mathrm{wp}} \\
(\%)\end{array}$ \\
\hline 1.5 & $4.37851(6)$ & $15.3765(5)$ & $0.330(2)$ & $0.130(3)$ & $2.73(2)$ & 4.3 & 7.5 & 7.6 & 7.1 \\
\hline
\end{tabular}

\section{Conclusion}

In this work we have demonstrated for the first time the possibility to insert both carbon and hydrogen atoms in the family of the equiatomic intermetallics RTX ( $R=$ rare earth, $T=$ transition metal, $X=p$ element). More specifically, the empty tetrahedral sites in the $\mathrm{NdScSiC} 0.5$ carbide can be partially filled with hydrogen by solid gas reaction at 40 bars and $450^{\circ} \mathrm{C}$. This causes a slight decrease in the $a$ parameter and an increase in the $c$ parameter, as observed upon hydrogenation of the intermetallic parent compound NdScSi. However, owing to the chemical pressure applied by the occupied C sites only $21(1) \%$ of the tetrahedral sites can be filled with hydrogen. This means that the presence of the $\mathrm{Nd}-\mathrm{C}$ bonding in the carbide hampers the formation of $\mathrm{Nd}-\mathrm{H}$ bonding. This small $\mathrm{H}$ occupancy is still sufficient to have a tremendous effect on the magnetic properties. Indeed, it changes the type of magnetism in $\mathrm{NdScSiC}_{0.5}$ from a ferromagnet with $\mathrm{T}_{\mathrm{c}}$ onset $=70 \mathrm{~K}$ to an antiferromagnet with $\mathrm{T}_{\mathrm{N}}=10 \mathrm{~K}$. The 
magnetic structure of $\mathrm{NdScSiC}{ }_{0.5} \mathrm{H}_{0.21}$ consists of double layers of ferromagnetic $\mathrm{Nd}$ moments aligned along the $c$ axis and coupled antiferromagnetically along this axis. Thus, hydrogenation of $\mathrm{NdScSiC}_{0.5}$ causes a change in the type of magnetic coupling between layers of $\mathrm{Nd}_{4}$ tetrahedra along the $c$ axis, along with a slight reduction of the $\mathrm{Nd}$ magnetic moment. This magnetic structure induces a field-induced metamagnetic transition that switches the antiferromagnetic state to a ferromagnetic one.

\section{References}

[1] C.N. Christodoulou, T. Takeshita, Preparation, structural and magnetic properties and stability of interstitial Sm2Fe17-carbonitrohydrides, J. Alloys Compd. 198 (1993) 1-24. https://doi.org/10.1016/0925-8388(93)90137-C.

[2] O. Isnard, S. Miraglia, J.L. Soubeyroux, D. Fruchart, J. Deportes, K.H.J. Buschow, Structural study and magnetic characterization of Th2Fe 17D5, Th2Fe17CxH 5-x and Th2Fe17N3, J. Phys. Condens. Matter. 5 (1993) 5481-5490. https://doi.org/10.1088/0953-8984/5/31/012.

[3] O. Isnard, J.L. Soubeyroux, D. Fruchart, T.H. Jacobs, K.H.J. Buschow, Structural and magnetic behaviour of the series Th2Fe17Cx ( $x=0$ to 1.25), J. Alloys Compd. 186 (1992) 135-145. https://doi.org/10.1016/0925-8388(92)90627-L.

[4] J.L. Soubeyroux, D. Fruchart, O. Isnard, S. Miraglia, E. Tomey, Role of the $(H, C, N)$ interstitial elements on the magnetic properties of iron-rare earth permanent magnet alloys, J. Alloys Compd. 219 (1995) 16-24. https://doi.org/10.1016/09258388(94)05017-1.

[5] V. Psycharis, M. Gjoka, O. Kalogirou, D. Niarchos, V. Papaefthymiou, C. Christodoulou, Magnetic properties of interstitial modified Pr3(Fe,Ti)29 hydrocarbide, J. Alloys Compd. 307 (2000) 234-239. https://doi.org/10.1016/S0925-8388(00)00741-6.

[6] H. Zhang, B.G. Shen, Z.Y. Xu, X.Q. Zheng, J. Shen, F.X. Hu, J.R. Sun, Y. Long, Reduction of hysteresis loss and large magnetocaloric effect in the C- and $\mathrm{H}$-doped $\mathrm{La}(\mathrm{Fe}, \mathrm{Si}) 13$ compounds around room temperature, J. Appl. Phys. 111 (2012) 1-4. https://doi.org/10.1063/1.3670608.

[7] C.S. Teixeira, M. Krautz, J.D. Moore, K. Skokov, J. Liu, P.A.P. Wendhausen, O. Gutfleisch, Effect of carbon on magnetocaloric effect of LaFe 11.6Si 1.4 compounds and on the thermal stability of its hydrides, J. Appl. Phys. 111 (2012) 11-14. https://doi.org/10.1063/1.3675985.

[8] H. Zhang, F.X. Hu, J.R. Sun, B.G. Shen, Effects of interstitial $H$ and/or $C$ atoms on the magnetic and magnetocaloric properties of $\mathrm{La}(\mathrm{Fe}, \mathrm{Si}) 13$-based compounds, Sci. China Physics, Mech. Astron. 56 (2013) 2302-2311. https://doi.org/10.1007/s11433-0135357-1. 
[9] X. Hai, F. Porcher, C. Mayer, S. Miraglia, Structural effects in the interstitial solid solution system ( $\mathrm{La}, \mathrm{Ce})(\mathrm{Fe}, \mathrm{Si}) 13 \mathrm{Cx}-\mathrm{H}$ : Correlation with hydrogenation kinetics, J. Appl. Phys. 123 (2018) 1-8. https://doi.org/10.1063/1.5013120.

[10] M. Phejar, V. Paul-Boncour, L. Bessais, Investigation on structural and magnetocaloric properties of LaFe13-xSix(H,C)y compounds, J. Solid State Chem. 233 (2016) 95-102. https://doi.org/10.1016/j.jssc.2015.10.016.

[11] B. Chevalier, W. Hermes, B. Heying, U.C. Rodewald, A. Hammerschmidt, S.F. Matar, E. Gaudin, R. Pöttgen, New Hydrides REScSiH and REScGeH (RE = La, Ce): Structure, magnetism, and chemical bonding, Chem. Mater. 22 (2010) 5013-5021. https://doi.org/10.1021/cm101290f.

[12] E. Gaudin, S.F. Matar, R. Pöttgen, M. Eul, B. Chevalier, Drastic Change of the Ferromagnetic Properties of the Ternary Germanide GdTiGe through Hydrogen Insertion, Inorg. Chem. 50 (2011) 11046-11054. https://doi.org/10.1021/ic201579r.

[13] I.A. Tskhadadze, V. V. Chernyshev, A.N. Streletskii, V.K. Portnoy, A. V. Leonov, I.A. Sviridov, I. V. Telegina, V.N. Verbetskii, Y.D. Seropegin, A. V. Morozkin, GdTiGe (CeScSitype structure) and GdTiGe (CeFeSi-type structure) as the coherent phases with different magnetic and hydrogenization properties, Mater. Res. Bull. 34 (1999) 17731787. https://doi.org/10.1016/S0025-5408(99)00159-2.

[14] S. Tencé, T. Mahon, E. Gaudin, B. Chevalier, J.L. Bobet, R. Flacau, B. Heying, U.C. Rodewald, R. Pöttgen, Hydrogenation studies on NdScSi and NdScGe, J. Solid State Chem. 242 (2016) 168-174. https://doi.org/10.1016/j.jssc.2016.02.017.

[15] T. Mahon, E. Gaudin, A. Villesuzanne, R. Decourt, J.L. Bobet, O. Isnard, B. Chevalier, S. Tencé, Hydrogen Insertion in the Intermetallic GdScGe: A Drastic Reduction of the Dimensionality of the Magnetic and Transport Properties, Inorg. Chem. 57 (2018) 14230-14239. https://doi.org/10.1021/acs.inorgchem.8b02247.

[16] T. Mahon, S. Tencé, R. Pöttgen, B. Chevalier, E. Gaudin, Study of the structural transition and hydrogenation of CeTiGe, J. Alloys Compd. 805 (2019) 701-708. https://doi.org/10.1016/j.jallcom.2019.07.104.

[17] T. Mahon, E. Gaudin, A. Villesuzanne, B. Chevalier, S. Tencé, Effect of Carbon Insertion on the Structural and Magnetic Properties of NdScSi, Inorg. Chem. (2019). https://doi.org/10.1021/acs.inorgchem.9b02260.

[18] J. Rodríguez-Carvajal, Recent advances in magnetic structure determination by neutron powder diffraction, Phys. B Phys. Condens. Matter. 192 (1993) 55-69. https://doi.org/10.1016/0921-4526(93)90108-I.

[19] V.F. Sears, Neutron scattering lengths and cross sections, Neutron News. 3 (1992) 2637. https://doi.org/10.1080/10448639208218770.

[20] C. Ritter, A. Provino, P. Manfrinetti, A.K. Pathak, Tetragonal to triclinic structural transition in the prototypical CeScSi induced by a two-step magnetic ordering: a temperature-dependent neutron diffraction study of CeScSi, CeScGe and LaScSi, J. Phys. Condens. Matter. 29 (2016) 45802. https://doi.org/10.1088/1361- 
$648 X / 29 / 4 / 045802$.

[21] H. Mizoguchi, S.W. Park, H. Hiraka, K. Ikeda, T. Otomo, H. Hosono, An anti CuO2-type metal hydride square net structure in $\mathrm{Ln} 2 \mathrm{M} 2 \mathrm{As} 2 \mathrm{Hx}(\mathrm{Ln}=$ la or $\mathrm{Sm}, \mathrm{M}=\mathrm{Ti}, \mathrm{V}, \mathrm{Cr}$, or $\mathrm{Mn}$ ), Angew. Chemie - Int. Ed. $54 \quad$ (2015) 2932-2935. https://doi.org/10.1002/anie.201409023.

[22] B.J.M. Mayer, L.E. Schneemeyer, T. Siegrist, J. V Waszczak, B. Van Dover, New Layered Iron-Lanthanum-Oxide-Sulfide and -Selenide Phases: $\mathrm{Fe}, \mathrm{La}, \mathrm{O}, \mathrm{E},(\mathrm{E}=\mathrm{S}, \mathrm{Se})^{* *}$, Angew. Chemie - Int. Ed. 31 (1992) 1645-1647.

[23] S.W. Park, H. Mizoguchi, H. Hiraka, K. Ikeda, T. Otomo, H. Hosono, Transformation of the Chromium Coordination Environment in LaCrAsO Induced by Hydride Doping: Formation of La2Cr2As2OyHx, Inorg. Chem. 56 (2017) 13642-13645. https://doi.org/10.1021/acs.inorgchem.7b02316.

[24] R.H. Liu, Y.A. Song, Q.J. Li, J.J. Ying, Y.J. Yan, Y. He, X.H. Chen, Structure and physical properties of the layered pnictide-oxides: $(\mathrm{SrF}) 2 \mathrm{Ti} 2 \mathrm{Pn} 2 \mathrm{O}(\mathrm{Pn}=\mathrm{As}, \mathrm{Sb})$ and $(\mathrm{SmO})$ 2Ti2Sb2O, Chem. Mater. 22 (2010) 1503-1508. https://doi.org/10.1021/cm9027258.

[25] H. Kabbour, E. Janod, B. Corraze, M. Danot, C. Lee, M.H. Whangbo, L. Cario, Structure and magnetic properties of oxychalcogenides $A 2 F 2 F e 2 O Q 2(A=S r, B a ; Q=S, S e)$ with Fe 20 square planar layers representing an antiferromagnetic checkerboard spin lattice, J. Am. Chem. Soc. 130 (2008) 8261-8270. https://doi.org/10.1021/ja711139g.

[26] W.L. Korst, J.C. Warf, Rare Earth-Hydrogen Systems. I. Structural and Thermodynamic Properties, Inorg. Chem. 5 (1966) 1719-1726. https://doi.org/10.1021/ic50044a018. 